\title{
Optimized coordinated control of LFC and SMES to enhance frequency stability of a real multi-source power system considering high renewable energy penetration
}

\author{
Gaber Magdy ${ }^{1,2^{*}}$ (D, G. Shabib ${ }^{2,3}$, Adel A. Elbaset $^{4}$ and Yasunori Mitani ${ }^{1}$
}

\begin{abstract}
With rapidly growing of Renewable Energy Sources (RESs) in renewable power systems, several disturbances influence on the power systems such as; lack of system inertia that results from replacing the synchronous generators with RESs and frequency/voltage fluctuations that resulting from the intermittent nature of the RESs. Hence, the modern power systems become more susceptible to the system instability than conventional power systems. Therefore, in this study, a new application of Superconducting Magnetic Energy Storage (SMES) (i.e., auxiliary Load Frequency Control (LFC)) has been integrated with the secondary frequency control (i.e., LFC) for frequency stability enhancement of the Egyptian Power System (EPS) due to high RESs penetration. Where, the coordinated control strategy is based on the PI controller that is optimally designed by the Particle Swarm Optimization (PSO) algorithm to minimize the frequency deviations of the EPS. The EPS includes both conventional generation units (i.e., non-reheat, reheat and hydraulic power plants) with inherent nonlinearities, and RESs (i.e., wind and solar energy). System modelling and simulation results are carried out using Matlab/ Simulink ${ }^{\otimes}$ software. The simulation results reveal the robustness of the proposed coordinated control strategy to preserve the system stability of the EPS with high penetration of RESs for different contingencies.
\end{abstract}

Keywords: Renewable energy sources (RESS), Load frequency control (LFC), Egyptian power system (EPS), Superconducting magnetic energy storage (SMES)

\section{Introduction}

Due to the growing demand on utilizing Renewable Energy Sources (RESs) as a future solution for energy shortages, many conventional generation units are being replaced by the RESs that have several impacts on the performance of the renewable power systems such as lack of system inertia. The RESs exchange electrical power with the power systems through power electronic devices (i.e., inverters and converters), which reduce the overall system inertia.
Consequently, the inverter-based RESs will cause high frequency/voltage fluctuations compared to the conventional generation units [1]. Moreover, the irregular nature of the RESs and random load deviations can cause severe power generation fluctuations. Therefore, the frequency control becomes more difficult in case of any mismatch between the power generation and the load demand, particularly, with high-level RESs (e.g., wind and solar energy) penetration into the power systems. Hence, the Load

\footnotetext{
* Correspondence: gabermagdy100@gmail.com

'Department of Electrical Engineering, Kyushu Institute of Technology,

Tobata-Ku, Kitakyushu-shi, Fukuoka 804-8550, Japan

${ }^{2}$ Department of Electrical Engineering, Faculty of Energy Engineering, Aswan

University, Aswan 81528, Egypt

Full list of author information is available at the end of the article
} 
Frequency Control (LFC) is considered one of the most important issues in power systems to maintain the system frequency and the power variations at their standard values. Whereas system frequency depends on active power and the system voltage greatly depends on the reactive power. Therefore, the control of power systems can be classified into two fundamental issues. a) control of the active power along with the frequency, b) control of the reactive power along with the voltage regulation [2].

To overcome the frequency instability problem, numerous control techniques for power system frequency control have been implemented such as fuzzy logic controller [3], artificial neural network (ANN) [4], linear quadratic regulator (LQR) controller [5] and robust controller-based $\mathrm{H}$ _infinte [6]. Although the control strategies [3-6] gave a good dynamic response, they are a dependency on the designer's experience and need long computational time. On the other hand, real-world LFC is performed based on Proportional-Integral-Derivative (PID) or PI controllers because of it has many merits such as; lower cost, simple structure, robustness performance and a successful practical controller that can provide excellent control performance regardless of the perturbations and variations in the system parameters [7]. However, these controllers suffer from a compli cated process of parameters tuning based on trial and error method. In such a case, the robustness of the system is not guaranteed against further perturbations in the system parameters. Therefore, several optimi zation algorithms were used to find the optimal parameters of the PI or PID controllers in the LFC loop such as particle swarm optimization (PSO) [8], cuckoo optimization algorithm [9], ant colony algorithm [10], quasi-oppositional harmony search algorithm (QOHSA) [11] etc.

According to the previous studies, most research has focused on the frequency stability analysis in power systems that are modelled as thermal power plants (i.e., non-reheat and reheat power plants) or/and hydraulic power plants depending on the number of areas. However, most of the existing realistic power systems comprise multi-source dynamic generators (e.g., thermal, hydraulic and gas power plants). Therefore, several types of power plants should be added to the LFC problem to achieve a realistic study as reported in this research. Furthermore, most of the studied power systems are linear and have a simple structure, where it mainly depends on the conventional generation units. However, several RESs should be integrated into the power systems to achieve more realistic study for the power systems of today. Therefore, recently, a few research and studies on the integration of several RESs into power systems have been conducted in [12-15]. However, based on the previous researches, the effects of a high penetration level of the RESs have not been considered for frequency stability analysis. Hence, several types of RESs with high penetration levels should be added in the analysis of the LFC issue for achievement more accurate studies for today's power systems.

With increasing the utilizing of RESs into the modern power systems, it becomes much important to look at methods and techniques to store this energy. Where, there are several Energy Storage Systems (ESSs) such as Superconducting Magnetic Energy Storage (SMES), electric batteries, fuel cells, and others, which have been considered within the design of the modern power systems [16]. Therefore, the ESSs can be used for storing the excess energy from the RESs, as well as, discharging the stored energy to the grid as needed, depending on demand. Among many ESSs, SMES is most suited for improved frequency stability in power systems, due to its outstanding advantages such as fast response, high efficiency, and long lifetime [17]. Therefore, a few research and studies on SMES applications for power systems have been conducted in $[18-21]$. According to the aforementioned references, there is no report for SMES system to analyze the frequency stability for a multi-source power system during high-level RESs penetration and contingencies. With increasing of penetration level of the RESs into the power systems, it will be caused higher frequency deviations and the LFC may be failing to maintain the system frequency. Therefore, from the perspective of the LFC, the SMES can be used as a feedback controller in the aim of supporting the frequency control loops (i.e., primary and secondary frequency controls) for frequency stability enhancement of the modern power system as reported in this research.

Based on the above analysis, this research proposes a coordinated control strategy between the secondary frequency control (i.e., LFC) and SMES unit (i.e., auxiliary LFC) for frequency stability enhancement of the EPS with high-level RESs penetration. Therefore, the main contribution of this work includes the following aspects. (i) this paper presents a real hybrid power system in Egypt that includes both conventional generation sources (i.e., steam, gas and hydraulic power plants) with inherent nonlinearities, and RESs (i.e., wind and solar energy) for studying the frequency stability analysis of such systems. Where, the conventional generation units in the EPS is decomposed into three dynamic subsystems; non-reheat, reheat and hydraulic power plants. Moreover, the physical constraints of the governors and turbines such as Generation Rate Constraints (GRCs) of 
power plants and speed governor deadband (GDB) are taken into consideration. (ii) this paper proposes a new application of SMES unit as a feedback controller in the aim of supporting the frequency control loops (i.e., primary and secondary frequency controls) for frequency stability enhancement of the studied power system. Where the dynamic structure of the studied SMES model in the previous researches $[2,18,20]$ is too simple and it is preferable to use a more realistic model. Moreover, the inductor current of the studied SMES model slowly returns to its nominal value after a system strike. However, the induction current of the SMES model must be quickly restored to its nominal value after a disturbance in the system so that it can respond to the next load disorder immediately. Therefore, restoring the inductor current to its nominal value can be enhanced by using the inductor current deviation as a negative feedback signal in the model of SMES control loop as reported in this study. (iii) the proposed coordinated control strategy of LFC and SMES unit is based on the PI controller that is optimally designed by the PSO algorithm to minimize the frequency deviations of the EPS. Moreover, the proposed coordinated can improve and maintain the frequency stability of the EPS and mainly when the RESs are highly penetrated at partial load. According to [22], the renewable power systems with the proposed coordinated control strategy will provide better stability and performance for the power systems of today, and for those of the future that is expected to integrate more and more RESs; thus, the proposed strategy will ensure an avoidance of system instability and system collapse.

The rest of this paper is structured as follows: Section 2 presents the system configuration including the EPS modelling and SMES technology modelling. The state-space dynamic modelling of the EPS considering RESs and SMES is described in section 3. Section 4 presents the control strategy and problem formulation. Section 5 describes the PSO algorithm. The simulation results and discussion are provided in section 6. Finally, the conclusion is presented in Section 7.

\section{System configuration}

\subsection{Modelling of the EPS}

The presented power system in this study is a real multi-source power system in Egypt, which has 180 power plants. Where, the power plants can be classified into 3 categories; a) Non-reheat power plants are represented by gas-turbine power plants and a few numbers of steam power plants. b) Reheat power plants are mainly represented by thermal power plants or combined cycle power plants. c) Hydraulic power plants such as High Dam in Aswan city. Recently, the EPS included several RESs such as wind and solar energy (e.g., photovoltaics (PV) solar power, and Concentrated Solar Power (CSP)). These RESs contribute almost $3 \%$ of the installed capacity. However, the Egyptian Electricity Holding Company (EEHC) aims to increase the electric energy from RESs to cover $20 \%$ of the electric energy demand by the year 2020 [23]. According to the last report of the EEHC in 2016, The total generation capacity and peak loads are $38,000 \mathrm{MW}$ and 29,000 MW respectively [23]. Motivated by the aforementioned observation, this paper focuses on modernization the EPS via integrating high-level RESs penetration, and SMES technology for facing the future challenges, which are expected to integrate more and more RESs. Therefore, the RESs includes wind power with a peak power of $5000 \mathrm{MW}$ and solar irradiation power with a peak power of $2300 \mathrm{MW}$. The base of the system frequency is $50 \mathrm{~Hz}$, while the power base is 38,000 MW. The EPS has been simulated and tested in this research to illustrate the proposed coordinated control strategy. The Egyptian grid studied power system case 9-machines and 32-bus system [24]. The single line diagram of the studied power system (i.e., The EPS) is shown in Fig. 1. Moreover, the simplified model of the EPS incorporation with RESs and SMES system is shown in Fig. 2. The National Energy Control Center (NECC) in Egypt has been advanced a dynamic model of Egyptian LFC in [25]. Therefore, this model will be modified using MATLAB/Simulink by adding high-level RESs integration and the dynamic contribution of the controllable SMES, which represents an auxiliary LFC alongside with the frequency control loops (i.e., primary and secondary frequency controls) for frequency stability analysis. Figure 3 shows the dynamic model of the EPS considering RESs with the proposed coordinated control strategy. The NECC in Egypt estimates the system parameters values, which used in the dynamic model of the EPS as indicated in Table 1.

The important inherent nonlinearities requirements and the physical constraints enjoined by the system dynamics of the generation units are taken into consideration to obtain an accurate perception for the EPS. One of the most important constraints of power plants is the rate of generation power change because of the limitation of mechanical movements. The physical system dynamics of power plants is represented by GRC and the maximum/minimum limit of the valve gate (i.e., governor deadband (GDB)). The GRC limits the generation rate of output power, which is given as $20 \% \mathrm{pu}$. MW/minute, and $10 \% \mathrm{pu} \mathrm{MW/minute} \mathrm{for} \mathrm{non-reheat} \mathrm{and} \mathrm{re-}$ heat turbines, respectively. However, the actual GRC of the hydraulic power plant is about $50 \%$ pu MW/minute, which is higher than the generation rate corresponding 


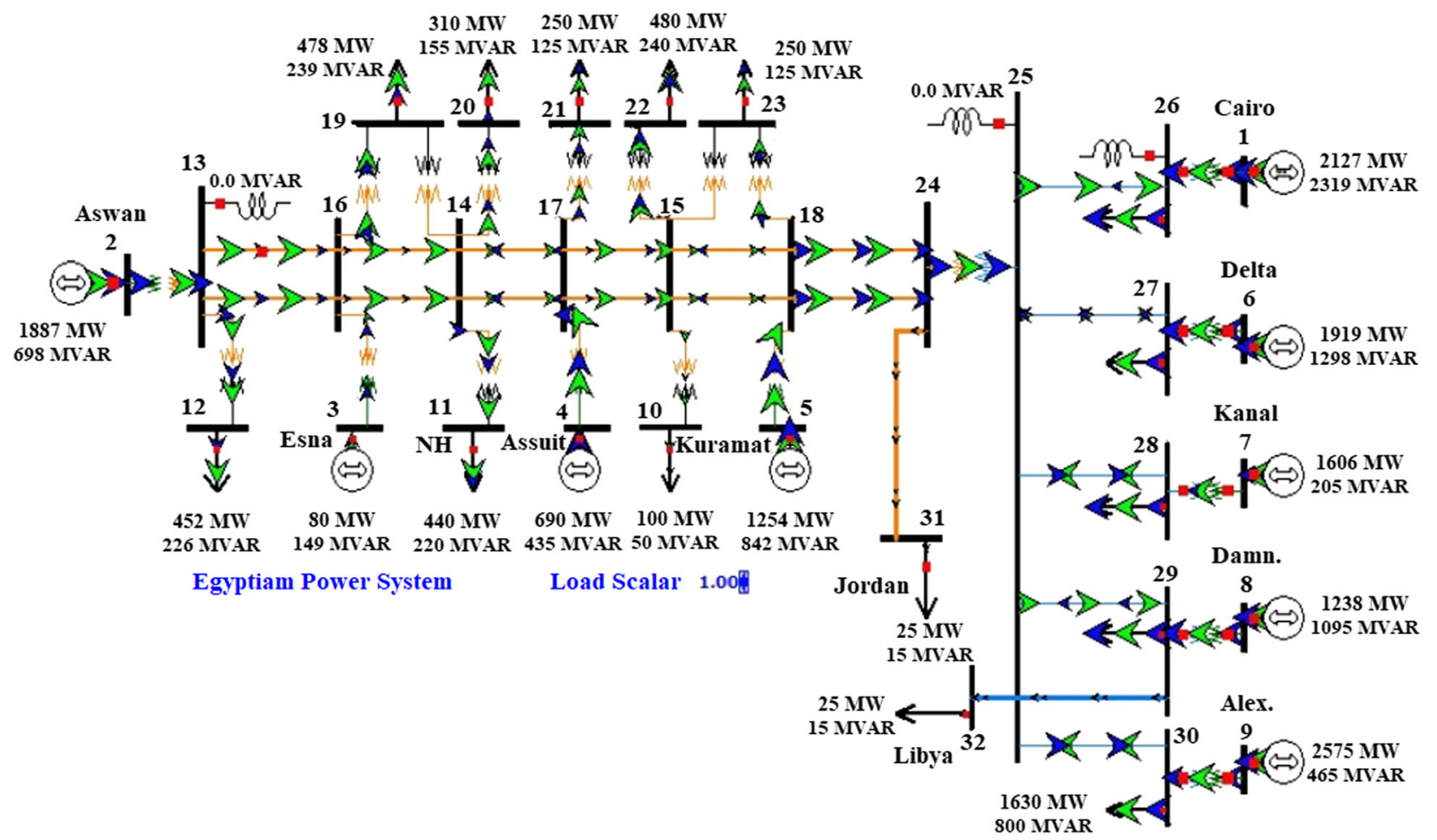

Fig. 1 A typical single-line diagram of the Egyptian Power System [24]

to any practical disturbance and hence it will be neglected [22]. On the other side, the GDB restricts the valve opening/closing. Where the GDB of the non-reheat and reheat power plants equal \pm 0.05 , while the GDB of the hydraulic power plant is \pm 0.01 . In this paper, the RESs have low-order dynamic models, which are considered sufficient for frequency stability analysis as reported in $[22,26]$. Therefore, the power variations of RESs; the wind power variation $\left(\Delta \mathrm{P}_{\mathrm{WT}}\right)$ and the PV solar power variation $\left(\Delta \mathrm{P}_{\mathrm{PV}}\right)$, and the load power variation $\left(\Delta \mathrm{P}_{\mathrm{L}}\right)$ are considered as disturbance signals to the EPS.

\subsection{Frequency control based on SMES system}

RESs such as wind, solar, waves, and tides are rapidly growing into today's power system. Where, the RESs

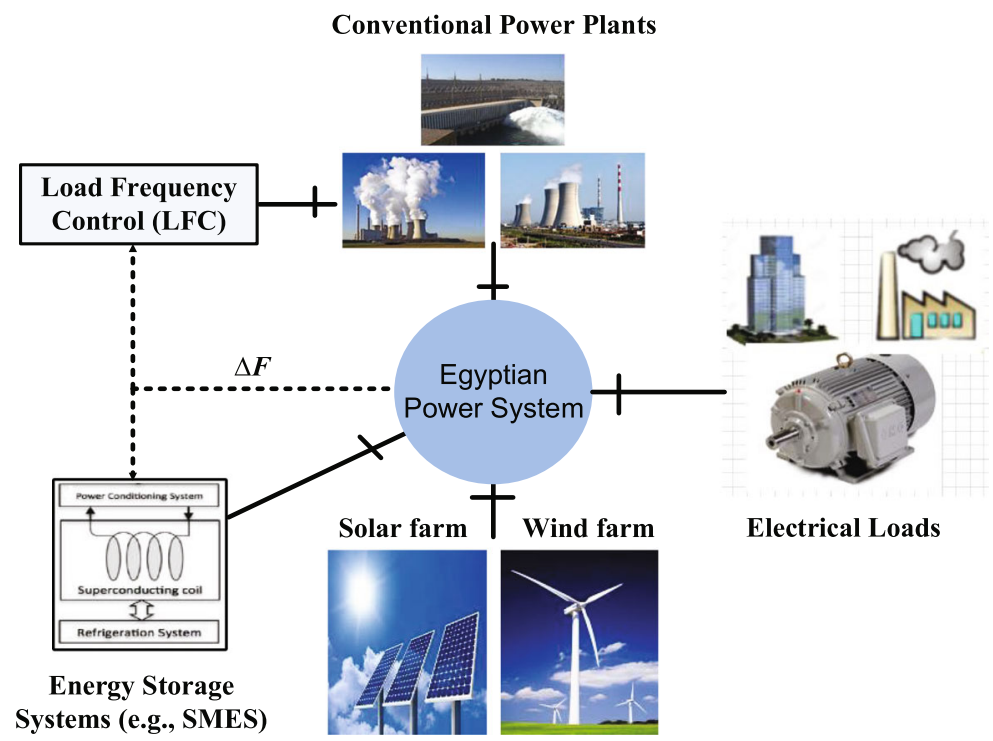

Fig. 2 A simplified model of the EPS with the proposed coordinated control strategy 


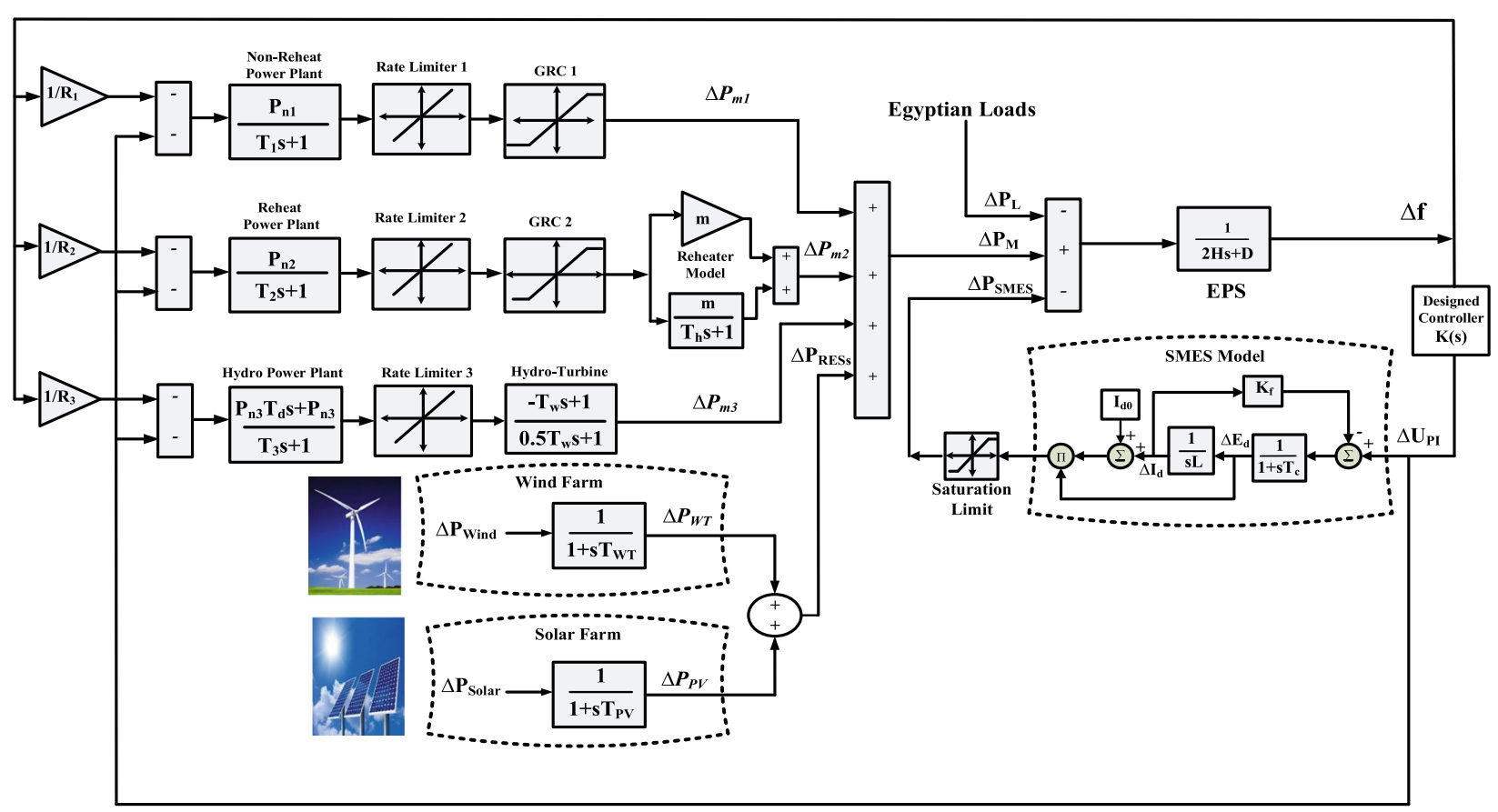

Fig. 3 A dynamic model of the EPS considering RESs with the proposed coordinated control strategy

exchange power to the power systems through power electronic devices that cause to reduce the system inertia and increase frequency/voltage fluctuations compared to the conventional generation units. Moreover, the intermittent nature of the RESs due to their outputs are dependent on weather will lead to more negative effects on system stability and the LFC may fail to readjust system frequency. These negative effects can limit high penetration of the RESs. Therefore, to overcome this problem, this paper proposes a new application of SMES system that uses as an auxiliary LFC incorporated with the primary and secondary frequency controls to enhance the frequency stability of the EPS with high RESs penetration.

The SMES technology is one of the most important energy storage devices, which is considered the most appropriate for frequency stability enhancement due to it

Table 1 System parameters of the studied power system

\begin{tabular}{llll}
\hline Parameter & Value & Parameter & Value \\
\hline $\mathrm{D}$ & 0.028 & $\mathrm{R}_{2}$ & 2.5 \\
$\mathrm{~T}_{1}$ & 0.4 & $\mathrm{R}_{3}$ & 1.0 \\
$\mathrm{~T}_{2}$ & 0.4 & $\mathrm{H}$ & 5.7096 \\
$\mathrm{~T}_{3}$ & 90 & $\mathrm{P}_{\mathrm{n} 1}$ & 0.2529 \\
$\mathrm{~T}_{\mathrm{d}}$ & 5 & $\mathrm{P}_{\mathrm{n} 2}$ & 0.6107 \\
$\mathrm{~T}_{\mathrm{h}}$ & 6 & $\mathrm{P}_{\mathrm{n} 3}$ & 0.1364 \\
$\mathrm{~T}_{\mathrm{w}}$ & 1.0 & $\mathrm{R}_{1}$ & 2.5 \\
$\mathrm{~m}$ & 0.5 & $\mathrm{f}$ & 50 \\
\hline
\end{tabular}

has many merits such as fast response, high efficiency, and long lifetime compared to other energy storage devices [17]. The SMES system storages the power in the magnetic coil, which made from a superconducting material with nearly zero loss of energy [19]. Where, the SMES unit comprises a dc superconducting magnetic coil, which is included in helium container, power electronic devices (i.e., inverter/converter) that are used to connect the dc magnetic coil to the ac power system, and $\Upsilon-\Delta / \Upsilon-\Upsilon$ transformer as shown in Fig. 4. The control of the firing angle $(\alpha)$ of the converter provides DC voltage that appears through an inductor (Ed) to continuously change within a given range of positive and negative values. The inductor is at first charged to its rated current $I_{d 0}$ by applying a little positive voltage. Once the current reaches the rated value, it is kept up steady by diminishing the voltage over the inductor to zero since the coil is superconducting [27]. Neglecting the losses of the transformer and the converter, the DC voltage is given by

$$
E_{d}=2 V_{d 0} \cos \alpha-2 I_{d} R_{C}
$$

The charging and discharging processes of the SMES unit can be controlled through variation of the commutation angle $(\alpha)$. The power conversion system acts in the converter mode (i.e., charging mode) When $\alpha<90^{\circ}$ but the power conversion system acts in the inverter mode (i.e., discharging mode) when $\alpha>90^{\circ}$. In this 


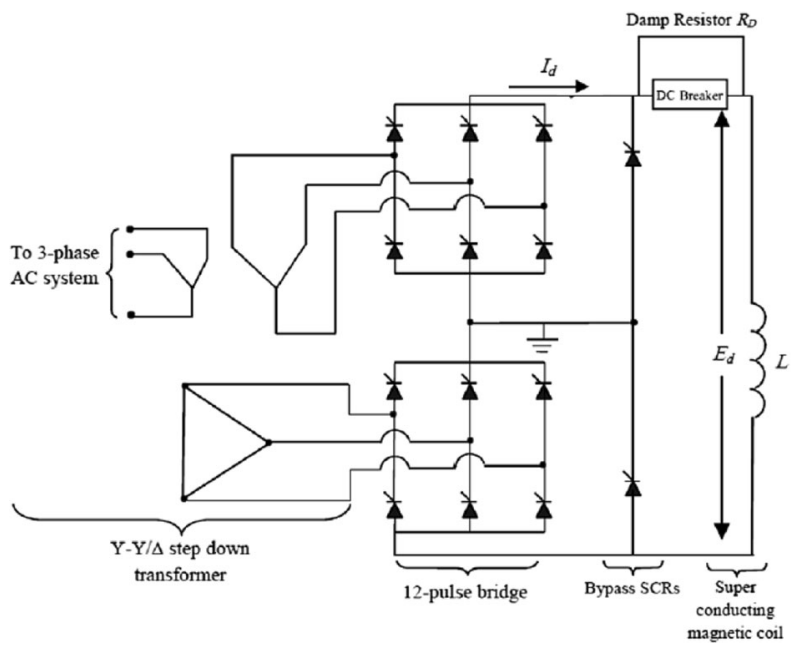

Fig. 4 The schematic diagram of the SMES unit

study, the SMES system is used as frequency stabilizer (i.e., auxiliary LFC), which can charge and discharge electrical power from/to the grid with very short time considering the SMES power limits. Therefore, the DC voltage of the superconducting inductor (Ed) is continuously controlled through the input signal of the SMES unit $\left(\mathrm{U}_{\mathrm{PI}}\right)$. Moreover, the current of the superconducting inductor must be quickly restored to its nominal value after a disturbance in the system so that it can respond to the next load disorder immediately. Consequently, the current deviation of the inductor can be detected and utilized as a negative feedback signal in the SMES control loop so that the current recovery can be enhanced to its nominal value [19]. Thus, the gradual change in the voltage applied to the inductor $(\Delta \mathrm{Ed})$ and the inductor current deviation $(\Delta \mathrm{Id})$ can be defined as follows:

$$
\begin{aligned}
& \Delta E_{d}=\frac{1}{1+s T_{c}}\left(\Delta U_{P I}-K_{f} \Delta I_{d}\right) \\
& \Delta I_{d}=\frac{\Delta E_{d}}{s L}
\end{aligned}
$$

The block diagram of the SMES control loop with the negative feedback of the inductor current deviation is included in the model of the EPS as shown in Fig. 3. Moreover, the SMES control loop parameters are given in Appendix [19]. Therefore, in this study, the designed SMES unit gives a good dynamic stability during the transients even when the system parameters are changed by $\pm 50 \%$ of their nominal values. Where the active power deviation of the SMES unit can be defined as:

$$
\Delta P_{S M E S}=\Delta E_{d}\left(\Delta I_{d}+I_{d 0}\right)
$$

The stored energy $\mathrm{E}$ (Joule) in the superconducting coil and its rated power P (Watt) are described by the following equations:

$$
\begin{aligned}
& E=\frac{1}{2} L I_{d o}{ }^{2} \\
& P=\frac{d E}{d t}=L I_{d o} \frac{d I_{d \mathrm{o}}}{d t}
\end{aligned}
$$

\section{State-space dynamic modelling}

The studied power system is considered ninth order linearized multi-source power system considering RESs and SMES system. The frequency deviation of the studied power system considering the effect of the primary control loop (i.e. governor action), a secondary control loop (i.e. LFC), and SMES controller (i.e. an auxiliary LFC) can be obtained as:

$$
\begin{gathered}
\Delta f=\frac{1}{2 H s+D}\left(\Delta P_{m 1}+\Delta P_{m 2}+\Delta P_{m 3}+\Delta P_{W T}+\Delta P_{P V}\right. \\
\left. \pm \Delta P_{S M E S}-\Delta P_{L}\right)
\end{gathered}
$$

Where

$$
\begin{aligned}
& \Delta P_{m 1}=\frac{P_{n 1}}{T_{1} S+1} *\left(\frac{-1}{R_{1}} * \Delta f-\Delta P_{c}\right) \\
& \Delta P_{g 2}=\frac{P_{n 2}}{T_{2} S+1} *\left(\frac{-1}{R_{2}} * \Delta f-\Delta P_{c}\right) \\
& \Delta P_{m 2}=\left(m+\frac{m}{T_{h} S+1}\right) * \Delta P_{g 2} \\
& \Delta P_{g 3}=\frac{P_{n 3} T_{d} S+P_{n 3}}{T_{3} S+1} *\left(\frac{-1}{R_{3}} * \Delta f-\Delta P_{c}\right) \\
& \Delta P_{m 3}=\left(\frac{-T_{w} S+1}{0.5 * T_{w} S+1}\right) * \Delta P_{g 3} \\
& \Delta P_{W T}=\frac{1}{T_{W T} S+1} *\left(\Delta P_{W i n d}\right) \\
& \Delta P_{P V}=\frac{1}{T_{P V} S+1} *\left(\Delta P_{\text {Solar }}\right) \\
& \Delta P_{S M E S}=\Delta E_{d}\left(\Delta I_{d}+I_{d 0}\right)
\end{aligned}
$$

Using Eqs. (7)-(15) and the dynamic model of the studied power system with the proposed coordinated control strategy as shown in Fig. 3, the dynamic equations of the studied hybrid power system can be derived and written in the state variable form as follows:

$$
\dot{X}=A X+B U+E W
$$

$$
Y=C X+D U+F W
$$


Hence, the complete state-space equations for the EPS considering RESs with the coordinated control strategy can be obtained as in (18).

\section{Control strategy and problem formulation}

The PID Controller has three terms functionality (i.e., P, I and D controllers) covering treatment to both transient and steady-state responses. However, the PID and P controllers cannot yield sufficient control performance with the consideration of nonlinearities and boiler dynamics [28]. To overcome this problem, the PI controller has been employed for system control. Therefore, the proposed coordinated control strategy is based on the PI controller in the EPS considering high-level RESs penetration and inherent nonlinearities. The PI controller has been validated to be remarkably effective in the regulating of a wide range of processes $[7,28]$. However, the PI controller suffers from a complicated process of parameters tuning-based trial and error method. Therefore, this research uses the PSO algorithm to find the optimum parameters of the PI controller for minimizing the system frequency deviation. Where, the PSO algorithm has

$$
\dot{\boldsymbol{X}}=\left[\begin{array}{ccccccccc}
-\frac{\boldsymbol{D}}{2 \boldsymbol{H}} & \frac{1}{2 \boldsymbol{H}} & \frac{1}{2 \boldsymbol{H}} & 0 & \frac{1}{2 \boldsymbol{H}} & 0 & \frac{1}{2 \boldsymbol{H}} & \frac{1}{2 \boldsymbol{H}} & \frac{1}{2 \boldsymbol{H}} \\
-\boldsymbol{a}_{1} & -\frac{1}{\boldsymbol{T}_{1}} & 0 & 0 & 0 & 0 & 0 & 0 & 0 \\
-\boldsymbol{m} \boldsymbol{a}_{2} & 0 & -\frac{1}{\boldsymbol{T}_{\boldsymbol{h}}} & \boldsymbol{b}_{1} & 0 & 0 & 0 & 0 & 0 \\
-\boldsymbol{a}_{2} & 0 & 0 & -\frac{1}{\boldsymbol{T}_{2}} & 0 & 0 & 0 & 0 & 0 \\
\left(-2 \boldsymbol{b}_{2} \boldsymbol{D}+2 \boldsymbol{a}_{3}+2 \boldsymbol{b}_{3}\right) & 2 \boldsymbol{b}_{2} & 2 \boldsymbol{b}_{2} & 0 & \left(2 \boldsymbol{b}_{2}-\frac{2}{\boldsymbol{T}_{\boldsymbol{w}}}\right) & \left(\frac{2}{\boldsymbol{T}_{\boldsymbol{w}}}+\frac{2}{\boldsymbol{T}_{3}}\right) & 0 & 0 & 0 \\
\left(\boldsymbol{b}_{2} \boldsymbol{D}-\boldsymbol{a}_{3}-\boldsymbol{b}_{3}\right) & -\boldsymbol{b}_{2} & -\boldsymbol{b}_{2} & 0 & -\boldsymbol{b}_{2} & -\frac{1}{\boldsymbol{T}_{3}} & 0 & 0 & 0 \\
0 & 0 & 0 & 0 & 0 & 0 & -\frac{1}{\boldsymbol{T}_{W T}} & 0 & 0 \\
0 & 0 & 0 & 0 & 0 & 0 & 0 & -\frac{1}{\boldsymbol{T}_{\boldsymbol{P V}}} & 0 \\
\frac{1}{\boldsymbol{T}_{C}} & 0 & 0 & 0 & 0 & 0 & 0 & 0 & -\frac{1}{\boldsymbol{T}_{\boldsymbol{C}}}
\end{array}\right]\left[\begin{array}{c}
\Delta \boldsymbol{f} \\
\Delta \boldsymbol{P}_{\boldsymbol{m} 1} \\
\Delta \boldsymbol{p}_{\boldsymbol{m} 2} \\
\Delta \boldsymbol{p}_{\boldsymbol{g}_{2}} \\
\Delta \boldsymbol{P}_{\boldsymbol{m} 3} \\
\Delta \boldsymbol{P}_{\boldsymbol{g}_{3}} \\
\Delta \boldsymbol{P}_{W \boldsymbol{T}} \\
\Delta \boldsymbol{P}_{\boldsymbol{P V}} \\
\Delta \boldsymbol{E}_{\boldsymbol{d}}
\end{array}\right]
$$

$$
\begin{aligned}
& +\left[\begin{array}{ccc}
0 & 0 & -\frac{1}{2 \boldsymbol{H}} \\
0 & 0 & 0 \\
0 & 0 & 0 \\
0 & 0 & 0 \\
0 & 0 & -2 \boldsymbol{b}_{2} \\
0 & 0 & \boldsymbol{b}_{2} \\
\frac{1}{\boldsymbol{T}_{W T}} & 0 & 0 \\
0 & \frac{1}{\boldsymbol{T}_{\boldsymbol{P V}}} & 0 \\
0 & 0 & 0
\end{array}\right]\left[\begin{array}{c}
\Delta \boldsymbol{P}_{\text {Wind }} \\
\Delta \boldsymbol{P}_{\text {Solar }} \\
\Delta \boldsymbol{P}_{\boldsymbol{L}}
\end{array}\right]+\left[\begin{array}{cc}
0 & 0 \\
-\frac{\boldsymbol{P}_{\boldsymbol{n} 1}}{\boldsymbol{T}_{1}} & 0 \\
-\frac{\boldsymbol{m} * \boldsymbol{P}_{\boldsymbol{n} 2}}{\boldsymbol{T}_{2}} & 0 \\
-\frac{\boldsymbol{P}_{\boldsymbol{n} 2}}{\boldsymbol{T}_{2}} & 0 \\
\frac{2 * \boldsymbol{P}_{\boldsymbol{n} 3}}{\boldsymbol{T}_{3}} & 0 \\
-\frac{\boldsymbol{P}_{\boldsymbol{n} 3}}{\boldsymbol{T}_{3}} & 0 \\
0 & 0 \\
0 & 0 \\
0 & -\frac{\boldsymbol{K}_{\boldsymbol{f}}}{\boldsymbol{T}_{\boldsymbol{C}}}
\end{array}\right]\left[\begin{array}{c}
\Delta \boldsymbol{P}_{\boldsymbol{C}} \\
\Delta \boldsymbol{I}_{\boldsymbol{d}}
\end{array}\right] \\
& \boldsymbol{Y}=\left[\begin{array}{lllllllll}
1 & 0 & 0 & 0 & 0 & 0 & 0 & 0 & 0
\end{array}\right]\left[\begin{array}{c}
\Delta \boldsymbol{f} \\
\Delta \boldsymbol{P}_{\boldsymbol{m} 1} \\
\Delta \boldsymbol{p}_{\boldsymbol{m} 2} \\
\Delta \boldsymbol{p}_{\boldsymbol{g} 2} \\
\Delta \boldsymbol{P}_{\boldsymbol{m} 3} \\
\Delta \boldsymbol{P}_{\boldsymbol{g} 3} \\
\Delta \boldsymbol{P}_{W \boldsymbol{T}} \\
\Delta \boldsymbol{P}_{\boldsymbol{P V}} \\
\Delta \boldsymbol{E}_{\boldsymbol{d}}
\end{array}\right]+\left[\begin{array}{lll}
0 & 0 & 0
\end{array}\right]\left[\begin{array}{c}
\Delta \boldsymbol{P}_{\text {Wind }} \\
\Delta \boldsymbol{P}_{\text {Solar }} \\
\Delta \boldsymbol{P}_{\boldsymbol{L}}
\end{array}\right]+\left[\begin{array}{ll}
0 & 0
\end{array}\right]\left[\begin{array}{c}
\Delta \boldsymbol{P}_{C} \\
\Delta \boldsymbol{I}_{\boldsymbol{d}}
\end{array}\right]
\end{aligned}
$$


many merits such as the ease of use, high convergence rates, minimum storage requirements, and less depending on the set of initial values, implying the robustness compared to other methods (i.e., genetic algorithm, artificial neural networks, fuzzy logic, and ant colony) [29]. Considering these advantages, this paper uses the PSO algorithm to tune the PI controller parameters, obtaining the optimum PI controller parameters with the robustness of operations. In this study, the integral of squared-error (ISE) is used as a fitness function that is

The constants of matrices are:

$a_{1}=\frac{P_{n 1}}{T_{1} R_{1}}, a_{2}=\frac{P_{n 2}}{T_{2} R_{2}}, a_{3}=\frac{P_{n 3}}{T_{3} R_{3}}, a_{4}=\frac{T_{d}}{2 H}, \quad b_{1}=\frac{2 m}{T_{h}}-\frac{m}{T_{2}}$, $b_{2}=a_{3} a_{4}, b_{3}=\frac{P_{3} T_{d}}{T_{3}}$

the objective function of the proposed optimization technique and can be formulated as follows:

$$
\text { ISE }=\int^{t s i m}(\Delta f)^{2} d t
$$

Subject to bounds of the PI controller parameters as follows:

$$
\left[K_{p, i}^{M i n} \leq K_{p, i} \geq K_{p, i}^{\operatorname{Max}}\right]
$$

where $(\Delta f)$ is the frequency deviation of the EPS and $t_{\text {sim }}$ is the simulation time to execute one run. The PSO algorithm is applied in the EPS to obtain the minimum value of the objective function (i.e., system frequency deviation) through getting on the optimal parameters of the PI controller.

\section{Optimal PI controller design based on PSO algorithm}

\subsection{Overview of particle swarm optimization}

The PSO is a global optimization algorithm based on evolutionary computation technique. It was presented by Kennedy and Eberhart in 1995 [30]. The basic operation principle of this optimization technique is developed on a swarm of birds flocking. The birds are either dispersed or go together from one place to another for searching their food. Furthermore, one of them can discover the place where the food can be found due to the transmitting information to other birds at any time while searching the food [31]. In the PSO algorithm, instead of using evolutionary operators, individuals called particle are used. Therefore, a swarm consist of several particles, each particle represents a potential for the problem. Each particle in the PSO algorithm flies in the search space according to its own flying experience and its companion flying experience. Each one of particles is treated as a particle in D-dimension search space. The position of particle represented as $X_{i}$, the best previous position of any particle is recorded and called Pbest. Another best value that is tracked by a global version of the PSO (i.e., the overall best value gbest) [32]. The

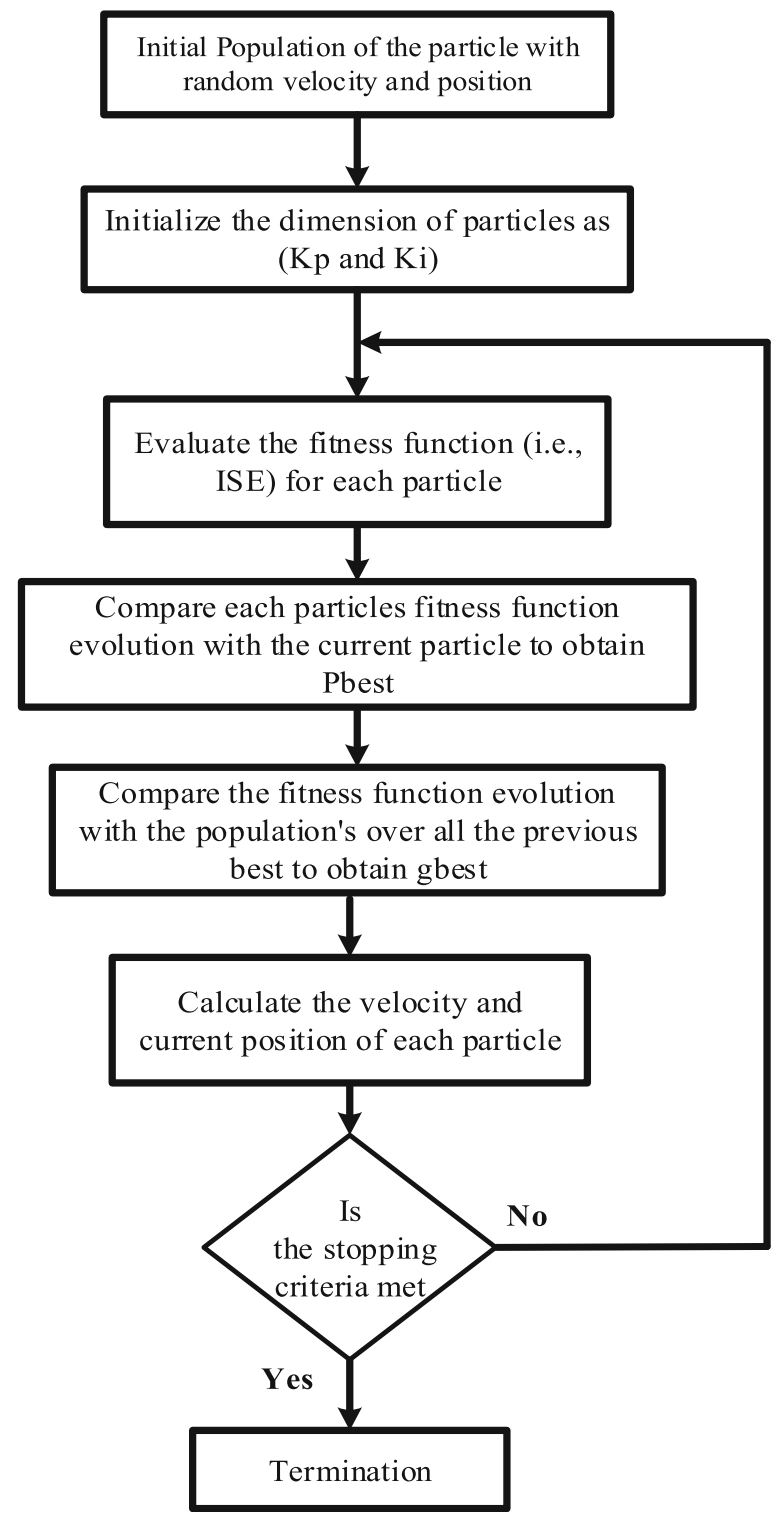

Fig. 5 Flowchart of PSO-PI controller

velocity of particle $\mathrm{i}$ is represented by $V_{i}$ and all particles are updated according to the following equations:

$$
\begin{aligned}
v_{i d}^{n+1}= & w \cdot V_{i d}^{n}+c_{1} \cdot \operatorname{rand}() \cdot\left(P_{i d}^{n}-X_{i d}^{n}\right) \\
& +c_{2} \cdot \operatorname{rand}() \cdot\left(P_{g d}^{n}-X_{i d}^{n}\right)
\end{aligned}
$$

Table 2 The control parameters of PSO

\begin{tabular}{ll}
\hline Parameter & Value \\
\hline Size of Swarm, S & 50 \\
Number of iterations, $\mathrm{n}$ & 50 \\
Inertia weight factor, $\mathrm{W}$ & 0.8 \\
Acceleration constant 1, $\mathrm{C}_{1}$ & 0.12 \\
Acceleration constant 2, $\mathrm{C}_{2}$ & 2 \\
\hline
\end{tabular}




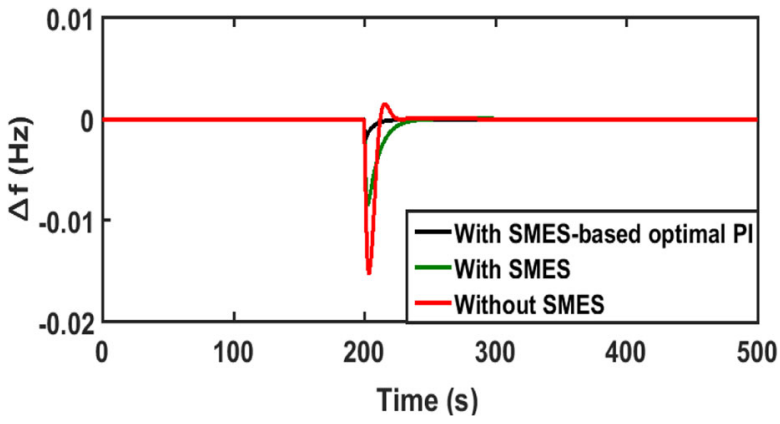

Fig. 6 The frequency deviation of the EPS for scenario 1

$$
x_{i d}^{n+1}=x_{i d}^{n}+v_{i d}^{\mathrm{n}+1}
$$

These equations are used to calculate the new values of velocity and position of each particle according to its previous values. Learning factors of the optimization technique have significant implications on the algorithm convergence rate. Further information for the PSO can be found in [29-33].

\subsection{Implementation of a PSO-PI controller}

This study uses the PSO algorithm to tune the PI controller gains $(K p$ and $K i)$ in the model of the EPS considering high penetration of RESs. Where, each particle in the search space introduces a probable solution for the PI gains, which are a 2-dimensional problem. The performance of the probable solution point is determined by the fitness function as seen in Eq. (19). Moreover, the size of the swarm determines the requirements of global optimization and computation time. Therefore, the steps of the PSO algorithm for optimum PI controller in the EPS are illustrated
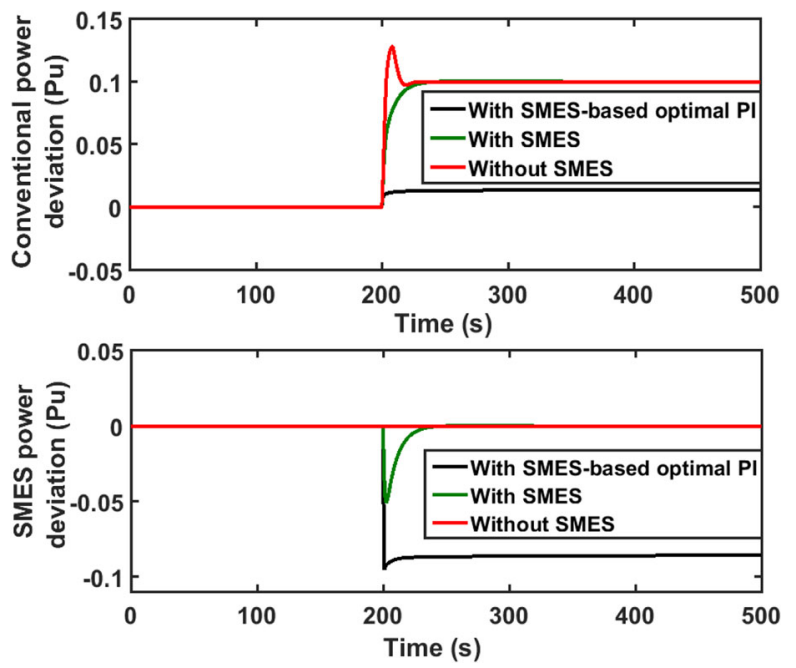

Fig. 7 Conventional generation and SMES power responses of the EPS for scenario 1
Table 3 The performance specification of the EPS for scenario 1

\begin{tabular}{llll}
\hline Scenario 1 & $\begin{array}{l}\text { With SMES-Based } \\
\text { optimal PI controller }\end{array}$ & With SMES & Without SMES \\
\hline MUS (pu) & $1.911 \times 10^{-3}$ & $8.401 \times 10^{-3}$ & $1.523 \times 10^{-2}$ \\
MOS (pu) & 0.0 & $6.440 \times 10^{-5}$ & $1.420 \times 10^{-3}$ \\
TS $_{\text {S }}$ & 17.297 & 26.703 & 27.421 \\
\hline
\end{tabular}

in Fig. 5. The performance of the PSO algorithm in searching the PI controller parameters of the coordinated control strategy in the EPS has been validated by using the characteristics of the PSO as given in Table 2. Where these optimal characteristics are considered enough after many trials. Therefore, the optimal parameters of the PI controller-based PSO algorithm under the system operation condition without RESs are $\{K p=7.48710$, and $K i=1.171355\}$, which produce the optimal control signal to the coordinated control strategy for frequency stability enhancement of the EPS when high RESs penetration. Where, the parameters of the PI controller lie in the range $[0$, 10], which are considered the most common values for LFC in the industry [34].

\section{Simulation results and discussions}

In this study, the coordinated control strategy between the secondary frequency control loop (i.e., LFC) and the SMES system (i.e., auxiliary LFC) is proposed for frequency stability enhancement of the EPS mainly when the RESs are highly penetrated.
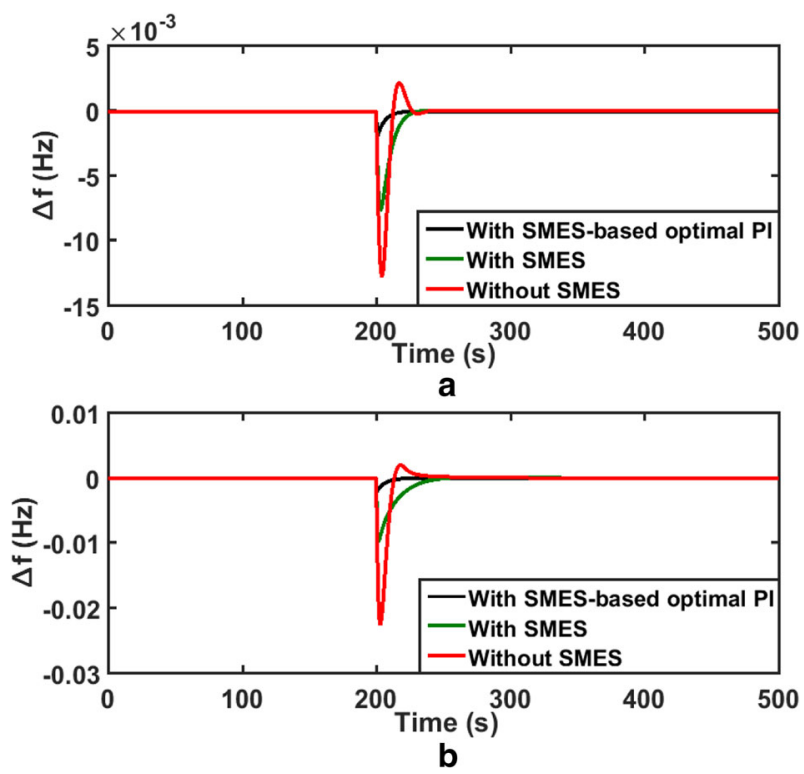

Fig. 8 The frequency deviation of the EPS for scenario 2: (a) $+50 \%$ system parameters variations, (b) $-50 \%$ system parameters variations 
Table 4 The performance specification of the EPS for scenario 2

\begin{tabular}{|c|c|c|c|c|c|c|c|c|c|}
\hline \multirow{2}{*}{$\begin{array}{l}\text { Scenario } \\
2\end{array}$} & \multicolumn{3}{|c|}{ With SMES-based optimal PI controller } & \multicolumn{3}{|l|}{ With SMES } & \multicolumn{3}{|l|}{ Without SMES } \\
\hline & MUS (pu) & MOS (pu) & $\mathrm{T}_{\mathrm{S}}(\mathrm{s})$ & MUS (pu) & MOS (pu) & $\mathrm{T}_{\mathrm{S}}(\mathrm{s})$ & MUS (pu) & MOS (pu) & $\mathrm{T}_{\mathrm{S}}(\mathrm{s})$ \\
\hline$+50 \%$ & $1.857 \times 10^{-3}$ & 0.0 & 15.848 & $7.548 \times 10^{-3}$ & $6.150 \times 10^{-5}$ & 23.424 & $1.266 \times 10^{-2}$ & $2.209 \times 10^{-3}$ & 26.723 \\
\hline$-50 \%$ & $1.982 \times 10^{-3}$ & 0.0 & 17.935 & $9.692 \times 10^{-3}$ & $1.249 \times 10^{-4}$ & 38.820 & $2.237 \times 10^{-2}$ & $2.042 \times 10^{-3}$ & 41.019 \\
\hline
\end{tabular}

Where, the proposed coordinated control strategy is based on the PI controller, which is optimally designed by the PSO algorithm to obtain the minimum value of the EPS frequency deviations. Moreover, the performance of the proposed coordinated control strategy is compared with both; the optimal LFC with/without SMES system under high-level RESs penetration and system parameters variations (i.e., system uncertainties). The simulation results of the studied power system are carried out using MATLAB/Simulink ${ }^{\bullet}$ software to validate the effective ness of the proposed coordinated control strategy. The code of the PSO as an m-file is interfaced with the model of the EPS to execute the optimization process. The EPS frequency stability with the proposed coordinated control strategy is investigated under different operating conditions through the following scenarios:

\subsection{System performance evaluation without the RESs}

The model of the studied power system (i.e., the EPS) without the RESs is considered as the test system to validate the effectiveness of the proposed coordinated control strategy for system frequency stability. The proposed coordinated control strategy using the designed PI controller-based PSO algorithm is tested by a sudden load change, which is represented as a step load perturbation (SLP) of $10 \% \mathrm{pu}$ at time $t=200 \mathrm{~s}$. Therefore, the sudden change in the load demand impacts on the EPS frequency stability can be obviously seen from these test scenarios:
Scenario 1: in this scenario, the studied power system (i.e., the EPS) is assumed to have the default parameters with $100 \%$ of default system inertia as indicated in Table 1. Figure 6 shows the EPS frequency deviations with the studied three control strategies. From Fig. 6, It is clear that the SMES controller can improve the frequency response and gives a better damped than the EPS without SMES. Compared to the EPS with/without the SMES controller, the proposed coordinated control strategy-based the optimal PI controller can provide a smooth and secure frequency performance. Therefore, the frequency response of the EPS is improved by using the proposed coordinated control strategy-based the optimal PI controller. Fig. 7 shows that the proposed coordinated control strategy success for decreasing the required power from the conventional generation units (i.e., non-reheat, reheat and hydraulic power plants) during the sudden load change at time $t=200 \mathrm{~s}$. Hence, the SMES power is greatly discharged by the proposed control strategy. The performance specifications; maximum overshoot (MOS), maximum undershoot (MUS), and maximum settling time $\left(\mathrm{T}_{\mathrm{S}}\right)$ of the EPS for this scenario have been compared in Table 3.

Scenario 2: in this scenario, the dynamic performance of the EPS with the proposed coordinated control strategy is investigated under system parameters variations (i.e., system uncertainties). The variable parameters are $T_{1}, T_{2}$, $T_{3}, T_{h}, T_{d}, T_{w}, m, R_{1}, R_{2}, R_{3}, H$, and $D$, which are
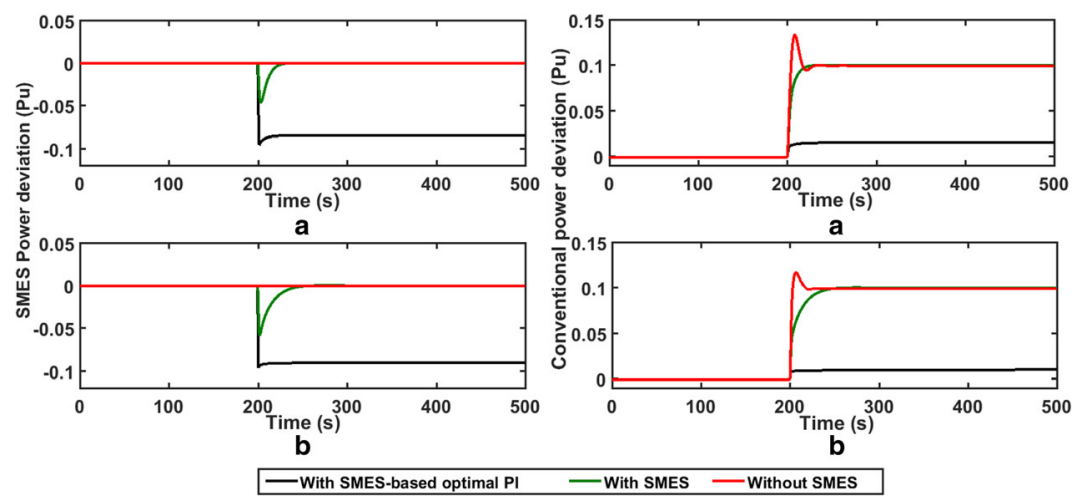

Fig. 9 Conventional generation and SMES power responses of the EPS for scenario 2: (a) + 50\% system parameters variations, (b) - $50 \%$ system parameters variations 

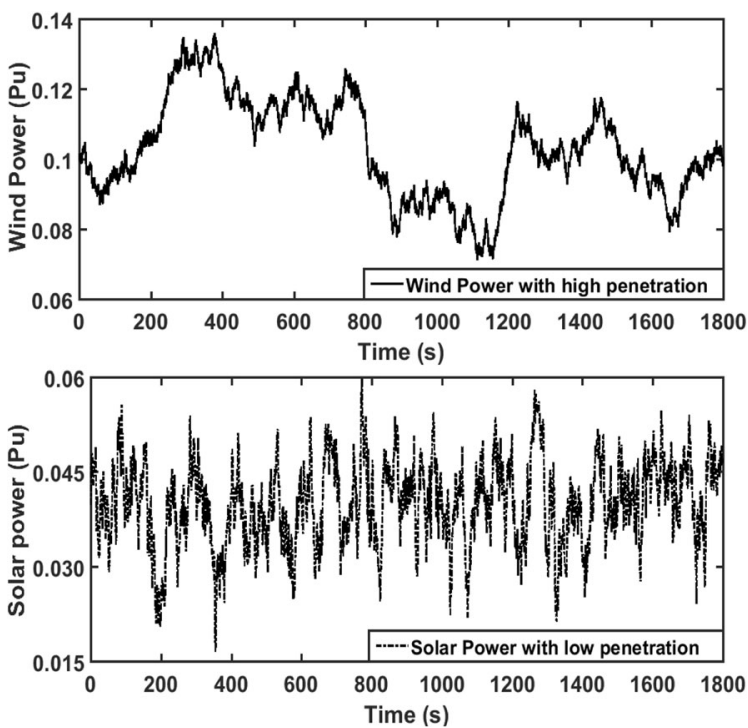

Fig. 10 Power variation of wind and solar power generations

changed by $\pm 50 \%$ of their nominal value. Figure 8 shows the frequency deviations of the studied power system with the proposed three control schemes under these conditions. It can be clear from these results the proposed coordinated control strategy can effectively regulate the system frequency and guarantee robust performance against system uncertainties. Furthermore, the settling time has lower values using the proposed control strategy than that by using other control strategies. Hence, the designed PI controller for the proposed coordinated control strategy is a robust controller where it does not need to re-tuning its parameters

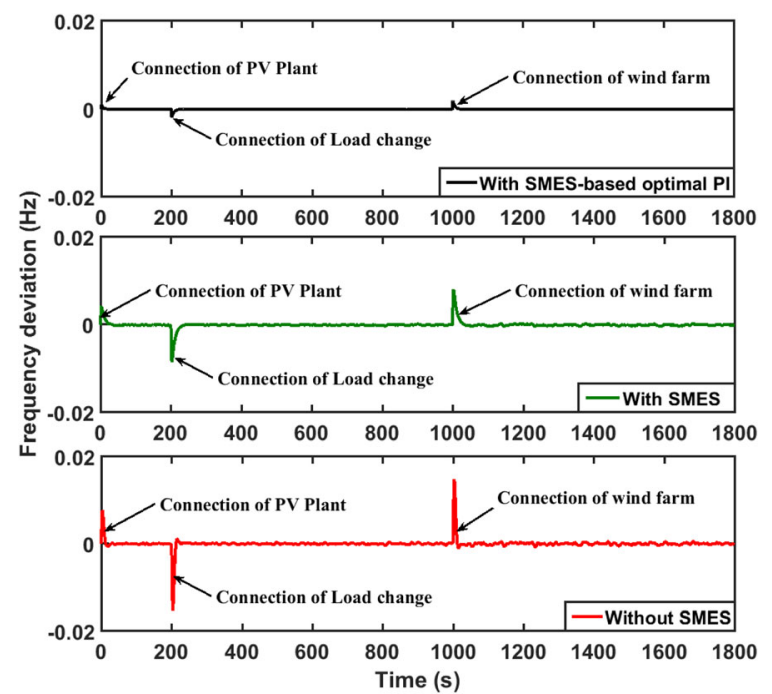

Fig. 11 The frequency deviation of the EPS for scenario 3
Table 5 The performance specification of the EPS for scenario 3

\begin{tabular}{llll}
\hline Scenario 3 & $\begin{array}{l}\text { With SMES-Based } \\
\text { optimal PI controller }\end{array}$ & With SMES & Without SMES \\
\hline MUS (pu) & $1.933 \times 10^{-3}$ & $8.358 \times 10^{-3}$ & $1.508 \times 10^{-2}$ \\
MOS (pu) & $1.908 \times 10^{-3}$ & $8.005 \times 10^{-3}$ & $1.469 \times 10^{-2}$ \\
$\mathrm{~T}_{\mathrm{S}}(\mathrm{s})$ & 19.432 & 26.288 & 27.001 \\
\hline
\end{tabular}

to deal with system uncertainties. The transient specification of the EPS like MOS, MUS, and $\mathrm{T}_{\mathrm{S}}$ is indicated in Table 4. Figure 9 shows that the conventional generation units significantly generated the needed power in cases of with/without SMES controller, while the proposed coordinated control strategy could significantly reduce the needed power from the conventional generation units during the sudden load change at time $t=200 \mathrm{~s}$. Moreover, the SMES power is greatly delivered by the proposed control strategy-based the optimal PI controller.

\subsection{System performance evaluation with the RESs}

The EPS considering high RESs penetration as shown in Fig. 3 is considered as the test system to confirm the robustness and effectiveness of the proposed coordinated control strategy. The proposed coordinated control strategy of LFC and SMES system (i.e., auxiliary LFC) using the designed PI controller-based PSO algorithm is tested by implementation; high fluctuated wind power at time $t=1000 \mathrm{~s}$, low fluctuated solar irradiation power at time $t=0 \mathrm{~s}$ and a sudden load change with $10 \% \mathrm{pu}$ at time $t=200 \mathrm{~s}$. Figure 10 shows the power variation of wind and solar power generations. Therefore, the EPS frequency stability with the proposed
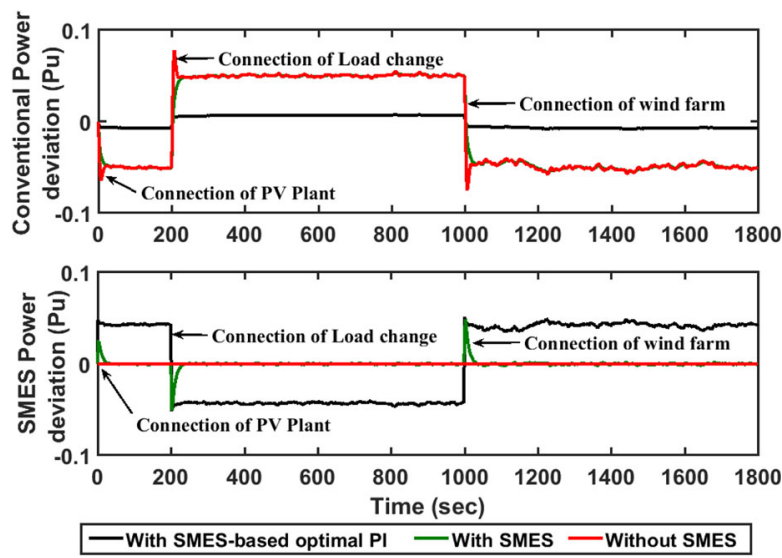

Fig. 12 Conventional generation and SMES power responses of the EPS for scenario 3 


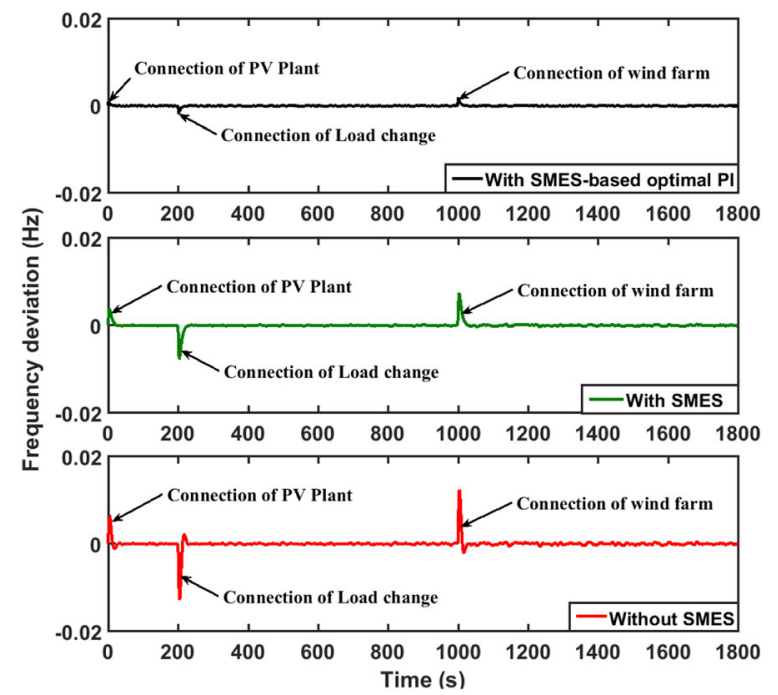

Fig. 13 The frequency deviation of the EPS for scenario 4, (+ $50 \%$ system parameters variations)

coordinated control strategy is investigated under different operating conditions through the following scenarios.

Scenario 3: in this scenario, the EPS considering high-level RESs penetration as seen in Fig. 3 is assumed to have the default parameters with $100 \%$ of default system inertia as indicated in Table 1. Figure 11 shows that the EPS frequency response is affected by the sudden load change and the RESs fluctuations. From Fig. 11, it can be noted that the system response using the proposed

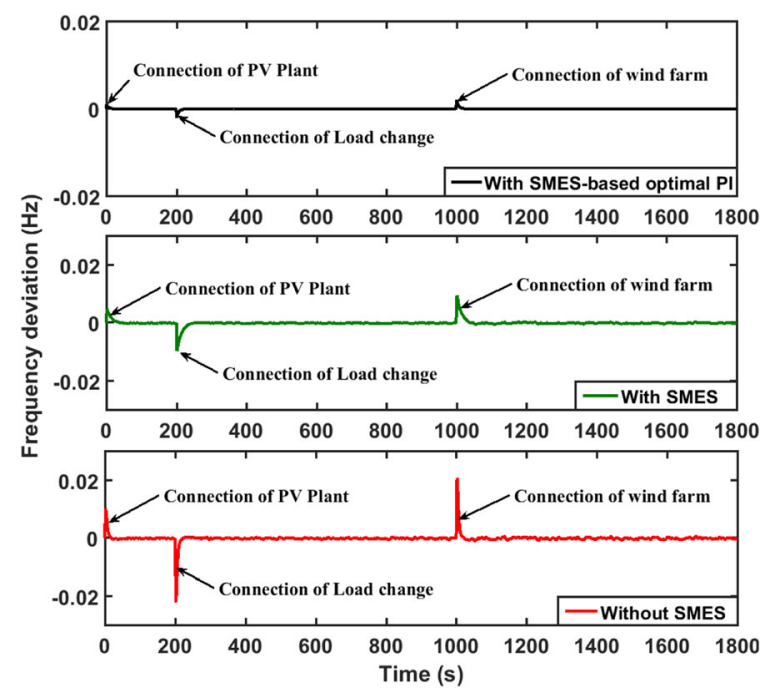

Fig. 14 The frequency deviation of the EPS for scenario 4 , ( $-50 \%$ system parameters variations) coordinated control strategy is faster, has a lower steady-state error and better damped than others control strategies. In addition, the numerical results of the transient specification (i.e., MOS, MUS, and $T_{S}$ ) for the three control strategies under these conditions are within acceptable ranges as indicated in Table 5. Hence, there is no need to redesign the designed optimal PI controller. On the other hand, in cases of the EPS with/without SMES controller, the conventional generation units significantly generated the needed power during the sudden load change at time $t=200 \mathrm{~s}$, while the proposed coordinated control strategy could significantly reduce the needed power from the conventional generation units as shown in Fig. 12. Moreover, the SMES power is greatly charged/discharged by the proposed coordinated control strategy from/to the EPS, according to the EPS needing.

Scenario 4: the main target of this scenario is to investigate the performance of the EPS with the proposed coordinated control strategy under variation in system parameters (i.e., system uncertainties). The default system parameters as indicated in Table 1 are changed by $\pm 50 \%$ of their nominal values. Figures 13 and 14 show the frequency deviations of the EPS with the three control strategies under these conditions. From these figures, it can be concluded that the proposed coordinated control strategy could address the system uncertainties and frequency deviation is quickly driven to zero. Where the proposed control strategy gives a little transient compared with the other control strategies. Furthermore, the numerical results of the transient specification (i.e., MOS, MUS, and TS) for the three proposed control schemes under variation in system parameters are very close to that of the nominal value of system parameters and within the acceptable ranges of the system frequency, according to the European network of transmission system operators for electricity codes [35], as indicated in Table 6. Although, the PI controller is very sensitive to the system uncertainty and non-linearity, which may be represented by the main demerit of this controller in some industrial applications [12]. It does not need retuning its parameters when the EPS considering high RESs penetration subjected to system uncertainties. This demonstrates the robustness and superiority of the proposed coordinated control strategy-based the optimal PI controller in regulation the system frequency in case of system parameters variations as well as high penetration level of the RESs. Figures 15 and 16 show the responses of the conventional generation sources and SMES power for the EPS under these condition of system uncertainties (i.e., $\pm 50 \%$ of system 
Table 6 The performance specification of the EPS for scenario 4

\begin{tabular}{|c|c|c|c|c|c|c|c|c|c|}
\hline \multirow{2}{*}{$\begin{array}{l}\text { Scenario } \\
4\end{array}$} & \multicolumn{3}{|c|}{ With SMES-based optimal PI controller } & \multicolumn{3}{|l|}{ With SMES } & \multicolumn{3}{|l|}{ Without SMES } \\
\hline & MUS (pu) & MOS (pu) & $\mathrm{T}_{\mathrm{S}}(\mathrm{s})$ & MUS (pu) & MOS (pu) & $\mathrm{T}_{\mathrm{S}}(\mathrm{s})$ & MUS (pu) & MOS (pu) & $\mathrm{T}_{\mathrm{S}}(\mathrm{s})$ \\
\hline$+50 \%$ & $1.850 \times 10^{-3}$ & $2.57 \times 10^{-5}$ & 17.869 & $7.56 \times 10^{-3}$ & $7.36 \times 10^{-3}$ & 24.512 & $1.269 \times 10^{-2}$ & $1.225 \times 10^{-2}$ & 27.018 \\
\hline$-50 \%$ & $2.015 \times 10^{-3}$ & $2.024 \times 10^{-3}$ & 18.559 & $9.681 \times 10^{-3}$ & $9.417 \times 10^{-3}$ & 26.142 & $2.188 \times 10^{-2}$ & $2.104 \times 10^{-2}$ & 27.119 \\
\hline
\end{tabular}

parameters) and high-level RESs penetration. From these figures, it is obvious that the conventional generation units largely generated the required power when applied a sudden load change at $\mathrm{t}=200 \mathrm{~s}$ in cases of the EPS with/without SMES, while the proposed coordinated control strategy could largely reduce the required power from the conventional generation units. Thus, the SMES power is fastly discharged by the proposed coordinated control strategy when the connection of load change, while the SMES power is greatly charged by the proposed coordinated control strategy when the connection of solar irradiation and wind power at time $\mathrm{t}=0 \mathrm{~s}$, and $\mathrm{t}=1000 \mathrm{~s}$, respectively.

\section{Conclusion}

Utilizing Renewable Energy Sources (RESs) is attracting great attention in today's power system to face the challenges of future energy shortages. However, the irregular nature of RESs and random load deviations cause large frequency/voltage fluctuations as well as reducing the system inertia that results from replacing the synchronous generators with RESs. Where these effects resulting from utilizing the RESs can limit their penetration. In order to benefit from a maximum capacity of the RESs, this paper proposes a new application of Superconducting Magnetic Energy Storage (SMES)
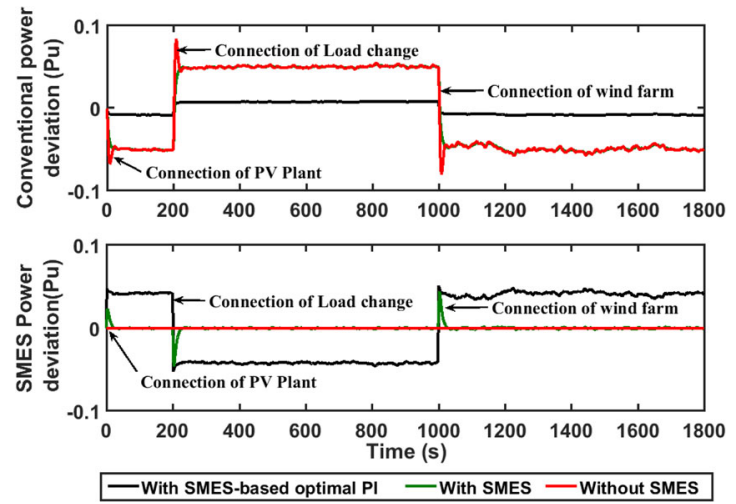

Fig. 15 Conventional generation and SMES power responses of the EPS for scenario 4, (+ 50\% system parameters variations) system based on an optimal PI controller that is optimally designed by the Particle Swarm Optimization (PSO) algorithm to enhance the frequency stability of the Egyptian Power System (EPS) considering high RESs penetration. Furthermore, the proposed SMES-based the optimal PI controller is coordinated with the secondary frequency control loop (i.e., Load Frequency Control (LFC)) for improvement and preservation the frequency stability of the EPS considering high RESs penetration. The conventional generation units in the EPS is decomposed into three dynamic subsystems; non-reheat, reheat and hydraulic power plants considering inherent nonlinearities (i.e., governor deadband and generation rate constraints of the power plants). To prove the effectiveness of the proposed coordinated control strategy, the EPS considering high-level RESs penetration has been tested using Matlab/SIMULINK ${ }^{\oplus}$ software. The simulations results proved that the proposed coordinated control strategy has achieved an effective performance for maintaining the EPS frequency stability. Hence, the proposed coordinated control strategy between the LFC and SMES system (i.e., auxiliary LFC) using the optimal PI controller-based the PSO algorithm will ensure an avoidance of power system instability and system collapse owing to high-level RESs integration.
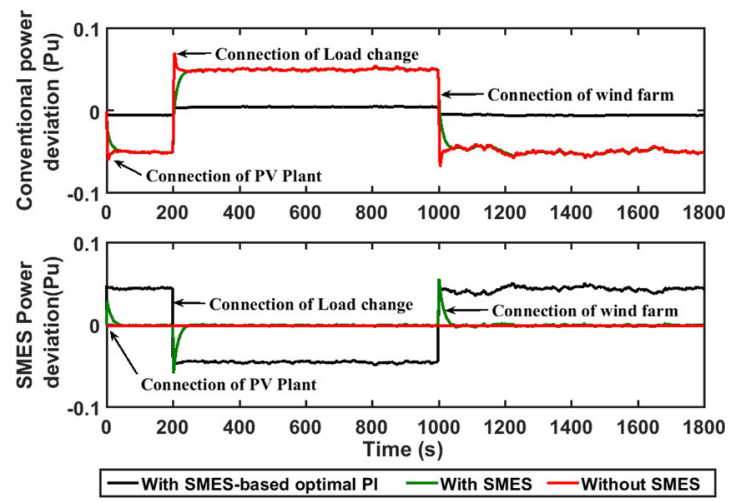

Fig. 16 Conventional generation and SMES power responses of the EPS for scenario 4, (- 50\% system parameters variations) 


\section{Appendix}

Table 8 SMES data [19] SMES control loop parameters are; $L=3 H, T_{C}=0.03, I_{\text {do }}=20 K A, K_{f}=0.001$

\begin{tabular}{|c|c|c|c|}
\hline \multicolumn{4}{|c|}{ Nomenclature } \\
\hline$\overline{\Delta f}$ & The frequency deviation of the EPS $(\mathrm{Hz})$ & $x_{i d}^{n}$ & The current position of particle $\mathrm{i}$ at iteration $\mathrm{n}$ \\
\hline $\mathrm{D}$ & System damping coefficient of the EPS (pu MW/Hz) & $v_{i d}^{n}$ & The velocity of particle i at iteration $n$ \\
\hline $\mathrm{H}$ & Equivalent inertia constant (pu sec) & $C_{1}, C_{2}$ & Acceleration constant \\
\hline $\mathrm{T}_{1}$ & Valve time constant of the non-reheat plant (sec) & $\mathrm{n}$ & Number of iterations \\
\hline $\mathrm{T}_{2}$ & Steam valve time constant of reheat plant (sec) & $P_{\text {id }}^{n}$ & pbest of particle i at iteration $n$ \\
\hline $\mathrm{T}_{3}$ & Water valve time constant hydro plant (sec) & $P_{g d}^{n}$ & gbest of particle i at iteration $n$ \\
\hline $\mathrm{T}_{\mathrm{d}}$ & Dashpot time constant of hydro plant speed governor (sec) & $\rho$ & Air density $\left(\mathrm{Kg} / \mathrm{m}^{3}\right)$ \\
\hline$T_{h}$ & The time constant of reheat thermal plant (sec) & $A_{T}$ & The rotor swept area $\left(\mathrm{m}^{2}\right)$ \\
\hline$T_{w}$ & Water starting time in hydro intake (sec) & $V_{W}$ & The rated wind speed $(\mathrm{m} / \mathrm{s})$ \\
\hline$\Delta \mathrm{P}_{\mathrm{L}}$ & Load variation (MW pu) & $C_{P}$ & The power coefficient of the rotor blades \\
\hline $\mathrm{m}$ & The fraction of turbine power (intermediate pressure section) & $P_{W}$ & The output power of the wind turbine $(\mathrm{W})$ \\
\hline $\mathrm{R}_{1}$ & Governor speed regulation non-reheat plant (Hz/pu MW) & $\beta$ & The pitch angle \\
\hline $\mathrm{R}_{2}$ & Governor speed regulation reheat plant (Hz/pu MW) & $r_{T}$ & The rotor radius \\
\hline $\mathrm{R}_{3}$ & Governor speed regulation hydro plant (Hz/pu MW) & $\lambda$ & The tip-speed ratio (TSR) \\
\hline$P_{n 1}$ & Nominal rated Power output for the non-reheat plant (MW pu) & $\mathrm{E}_{\mathrm{d}}$ & The dc voltage applied to the inductor (KV) \\
\hline$P_{n 2}$ & Nominal rated Power output for reheat plant (MW pu) & $V_{\text {do }}$ & The maximum bridge circuit voltage (KV) \\
\hline$P_{n 3}$ & Nominal rated Power output for the hydro plant (MW pu) & a & The firing angle (degree) \\
\hline$\Delta P_{c 1}$ & Regulating the system frequency of non-reheat plant $(\mathrm{Hz})$ & $l_{d}$ & The current through the inductor (KA) \\
\hline$\Delta P_{c 2}$ & Regulating the system frequency of reheat plant $(\mathrm{Hz})$ & $\mathrm{R}_{c}$ & The equivalent commutation resistance (KS) \\
\hline$\Delta P_{c 3}$ & Regulating the system frequency of hydro plant $(\mathrm{Hz})$ & $K_{f}$ & The feedback gain of the inductor current deviation \\
\hline $\mathrm{T}_{\mathrm{WT}}$ & Wind turbine time constant (sec) & $T_{c}$ & The converter time delay \\
\hline $\mathrm{T}_{\mathrm{PV}}$ & Solar system time constant (sec) & $L$ & The coil inductance $(\mathrm{H})$ \\
\hline W & Inertia weight factor & $\triangle P_{S M E S}$ & The active power deviation of SMES unit \\
\hline rand () & A random number between 0 and 1 & & \\
\hline
\end{tabular}

\section{Acknowledgements}

Not applicable.

\section{Funding}

This paper was funded by the Cultural Affairs and Missions Sector of the Egyptian Ministry of Higher Education.

\section{Availability of data and materials}

Data sharing not applicable to this article as no datasets were generated or analyzed during the current study.

\section{Authors' contributions}

GM as a corresponding author, contributed significantly to analysis, manuscript preparation and manuscript submission. GS, AAE and YM as supervisors helped to perform the study analysis with constructive discussions, professional advice and revised the manuscript. All authors read and approved the final manuscript.

\section{Competing interests}

The authors declare that they have no competing interests.

\section{Author details}

'Department of Electrical Engineering, Kyushu Institute of Technology, Tobata-Ku, Kitakyushu-shi, Fukuoka 804-8550, Japan. ${ }^{2}$ Department of Electrical Engineering, Faculty of Energy Engineering, Aswan University, Aswan 81528, Egypt. ${ }^{3}$ Higher Institute of Engineering and technology, King Marriott, Alexandria 23713, Egypt. ${ }^{4}$ Department of Electrical Engineering, Faculty of Engineering, Minia University, Minia 61517, Egypt.
Received: 10 August 2018 Accepted: 26 November 2018

Published online: 28 December 2018

\section{References}

1. Rakhshani, E., Remon, D., Cantarella, A., et al. (2016). Analysis of derivative control based virtual inertia in multi-area high-voltage direct current interconnected power systems. IET Gener Trans Distrib, 10(6), 1458-1469.

2. Magdy, G., Mohamed, E. A., Shabib, G., et al. (2018). SMES based a new PID controller for frequency stability of a real hybrid power system considering high wind power penetration. IET Renewable Power Generation, 12(11), 1304-1313.

3. Cam, E., Gorel, G., \& Mamur, H. (2017). Use of the genetic algorithm-based fuzzy logic controller for load-frequency control in a two area interconnected power system. App/ Sci, 7(3), 1-22.

4. Nasiruddin, I., Sharma, G., Niazi, K. R., et al. (2017). Non-linear recurrent ANN -based LFC design considering the new structures of Qmatrix. IET Generation Trans Distribut, 11(11), 2862-2870.

5. Shahalami, S. H., \& Farsi, D. (2018). Analysis of load frequency control in a restructured multi-area power system with the Kalman filter and the LQR controller. Int J Electron Commun, 86(1), 25-46.

6. Sun, Y., Wang, Y., Wei, Z., et al. (2018). Robust Ha load frequency control of multi-area power system with time delay: A sliding mode control approach. IEEE/CAA J Auto Sin, 5(2), 1-8.

7. Shabib, G., Abd-Elhamed, E. H., \& Magdy, G. (2018). Robust digital redesign of continuous PID controller for power system using plant-input-mapping. WSEAS Trans Power Syst, 13(1), 31-39.

8. Illias, H., Fikri, A., Zahari, M., et al. (2016). Optimisation of PID controller for load frequency controller in two-area power system using evolutionary particle swarm optimisation. Int J Elect Syst, 12(2), 315-324. 
9. Gheisarnejad, M. (2018). An effective hybrid harmony search and cuckoo optimization algorithm based fuzzy PID controller for load frequency control. Appl Soft Comput, 65(1), 121-138.

10. El-Saddy, G., Ibrahim, E. A., \& Donkol, A. A. (2017). Ant Colony PID Controllers for Nonlinear Load Frequency Control System. Int J Power Eng Energy, 8(1), 719-724.

11. Shankar, G., \& Mukherjee, V. (2016). Load frequency control of an autonomous hybrid power system by quasi-oppositional harmony search algorithm. Elect Power Energy Syst, 78(1), 715-734.

12. Hasanien, H. M. (2017). Whale optimization algorithm for obtaining the optimal PID controller parameters in interconnected modern power system including renewable sources. IET Gener Transm Distrib, 12(3), 607-616.

13. Ma, M., Liu, X., \& Zhang, C. (2017). LFC for multi-area interconnected power system concerning wind turbines based on DMPC. IET Generation Trans Distrib, 11(10), 2689-2686.

14. Kouba, N. E., Menaa, M., Hasni, M., et al. (2016). LFC enhancement concerning large wind power integration using new optimised PID controller and RFBs. IET Generation Trans Distrib, 10(16), 4065-4077.

15. El-Fergany, A. A., \& El-Hameed, M. A. (2017). Efficient frequency controllers for autonomous two-area hybrid microgrid system using social-spider optimiser. IET Generation Trans Distrib, 11(3), 637-648.

16. Marzband, M., Ghazimirsaeid, S. S., Uppal, H., et al. (2017). A real-time evaluation of energy management systems for smart hybrid home microgrids. Electr Power Syst Res, 143(1), 624-633.

17. Amrouche, S. O., Rekiouab, D., Rekiouab, T., et al. (2016). Overview of energy storage in renewable energy systems. Int J Hydrog Energy, 41(45), 20914-20927.

18. Zargar, M. Y., Mufti, M. U., \& Lone, S. A. (2017). Adaptive predictive control of a small capacity SMES unit for improved frequency control of a wind-diesel power system. IET Renewable Power Generation, 11(1), 1832-1840.

19. Khosraviani, M., Jahanshahi, M., Farahani, M., et al. (2018). Load-frequency control using multi-objective genetic algorithm and hybrid sliding mode control-based SMES. Int J Fuzzy Syst, 20(1), 280-294.

20. Magdy, G., Shabib, G., Elbaset, A. A., et al. (2018). A robust control strategy for mitigating renewable energy fluctuations in a real hybrid Powe system combined with SMES. AIP Conf Proc, 1968(1), 1-12.

21. Padhan, S., Sahu, R. K., \& Panda, S. (2014). Automatic generation control with thyristor-controlled series compensator including superconducting magnetic energy storage units. Ain Shams Eng J, 5(1), 759-774.

22. Bevrani, H. (2014). 'Robust power system frequency Control' (2nd ed.). New York: springer.

23. Egyptian Electricity Holding Company, Annual Report, available at: http:// www.eehc.gov.eg/eehcportal/YearlyReports.aspx, 2016

24. Mobarak, Y. A. (2015). Voltage collapse prediction for Egyptian interconnected electrical grid EIEG. Int J Elec Eng Inform, 7(1), 79-88.

25. Magdy, G., Bakeer, A., Shabib, G., et al. (2017). Decentralized Model Predictive Control Strategy of a Realistic Multi Power System Automatic Generation Control'. IEEE Conf., 16th international Middle East power systems conference (MEPCON'19) (pp. 190-196). Egypt: Menoufia University.

26. Bevrani, H., Habibi, F., Babahajyani, P., Watanabe, M., \& Mitani, Y. (2012). 'Intelligent frequency control in an AC microgrid: Online PSO-based fuzzy tuning approach', IEEE trans. Smart Grid, 3(4), 1935-1944.

27. Abraham, R. J., Das, D., \& Patra, A. (2007). Automatic generation control of an interconnected hydrothermal power system considering superconducting magnetic energy storage. Electrical Power Energy Syst, 29(1), 571-579.

28. Bhanu, P., Bhushan, C., Sujatha, K., et al. (2011). Load Frequency Controller with PI Controller Considering non-Linearities and Boiler Dynamics (pp. 290-294). India: 2nd international conference on sustainable energy and intelligent system (SEISCON).

29. Kerdphol, T., Qudaih, Y., \& Mitani, Y. (2016). Optimum battery energy storage system using PSO considering dynamic demand for microgrids. Electrical Power and Energy Syst, 83(1), 58-66.

30. Kennedy, J., \& Eberhart, R. C. (1995). 'Particle swarm optimization', proc. IEEE Int Conf Neural Net Perth, Aust IEEE Service Center Piscataway, 4(1), 1942-1948.

31. Ang, K. H., Chong, G., \& Li, Y. (2005). PID control system analysis, design, and technology. IEEE Trans on Control Syst Technol, 13(4), 559-576.

32. Gaing, Z. L. (2004). A particle swarm optimization approach for optimum design of PID controller in AVR system. IEEE Trans on Energy Conversion, 19(2), 384-391.

33. Valarmathi, K., Devaraj, D., \& Radhakrishnan, T. K. (2005). Particle Swarm Optimization based PI Controller Tuning for Fermentation Process (pp. 1-6).
Vienna: IEEE Conf., International conference on computational intelligence for modelling, Control and Automation.

34. Abd-Elazim, S. M., \& Ali, E. S. (2016). Load frequency controller design via BAT algorithm for nonlinear interconnected power system. Int J Electr Power Energy Syst, 77(1), 166-177.

35. European Network of Transmission System Operators for Electricity (ENTSOE). (2013). Supporting Document for the Network Code on Load-Frequency Control and Reserves,' chapter 4 (pp. 17-36).

\section{Submit your manuscript to a SpringerOpen ${ }^{\circ}$ journal and benefit from:}

- Convenient online submission

- Rigorous peer review

- Open access: articles freely available online

- High visibility within the field

- Retaining the copyright to your article

Submit your next manuscript at $>$ springeropen.com 